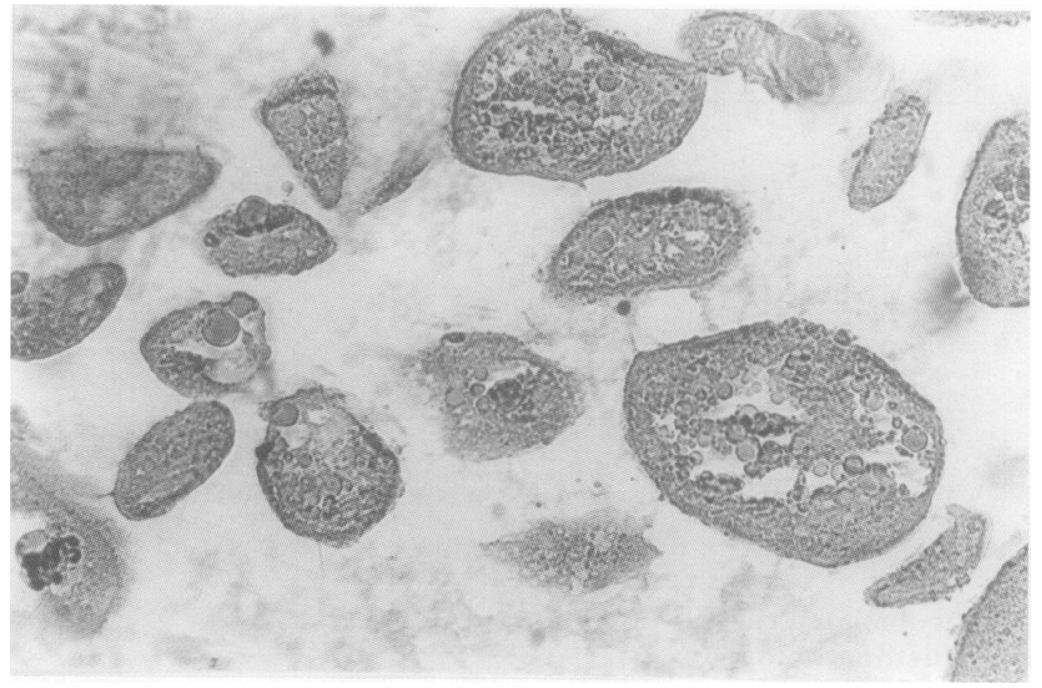

Figure 2 Higher power image showing parent bodies enclosing several round refractile structures of varying sizes (endobodies) (haematoxylin and eosin, $\times 450$ ).

sure of red blood cells, which had extravasated because of the congestion and vasodilation associated with conjunctivitis, to the fat released from the fat based antibiotic ointment applied topically. It is unlikely that the lesion in the present case resulted from tissue disruption induced by prior trauma or any associated malignancy.

The diagnosis of spherulocystosis can only be made after the histopathological examination of the resected tissue. At histology, the large sac-like structures (parent bodies), measuring $60-100 \mu \mathrm{m}$ in diameter, contained several smaller spherules (endobodies), measuring $4-10 \mu \mathrm{m}$ in diameter. ${ }^{7}$ The spherules are light brown on staining with haematoxylin and eosin as they are made up of acid haematin, which is a degradation product of haemoglobin. ${ }^{1}$ However, in smears, the spherules are best seen with the Papanicolaou stain ${ }^{6}$, with which they are stained varying shades of green and orange.

The spherules can be confused with fungi, algae of genus Prototheca, vegetable matter, and pollen grains. ${ }^{1}$ The spherules are most easily confused with incoccidioidomycosis and rhinosporidiosis, and can be differentiated from the latter by careful light microscopy, by the lack of staining with periodic acid Schiff and Gomori methenamine silver stains and also by positive immunostaining for haemoglobin. Although spherulocytosis may be associated with inflammation, in the present case, however, this was minimal.

To the best of our knowledge, in the English literature, this is the first case of spherulocystosis (myospherulosis) confined to the eye and caused by topically applied antibiotic ointment.

Rosai J. The nature of myospherulosis of the upper respiratory tract Am ₹ Clin Pathol 1978;69:475-81.

2 McClatchie S, Warambo MW, Bremner AD. Myospheru losis: a previously unreported disease? Am $尹$ Clin Pathol 1969;51:699-704

3 Lazarov A, Avinoach I, Giryes H, Halevy S. Dermal spherulosis (myospherulosis) after topical treatment for psoriasis. f Am Acad Dermatol 1994;30:265-7.

Kyriakos M. Myospherulosis of the paranasal sinuses, nose and middle ear. Am f Clin Pathol 1977;76:118-30.

Mills SE, Lininger JR. Intracranial myospherulosis. Hum Pathol 1982;13:596-7.

6 Shabb N, Sneige N, Dekmezian RH. Myospherulosis. Fine needle aspiration cytologic findings in 19 cases. Acta Cytol 1991:35:225-8.

7 Kakizaki H, Shimada K. Experimental study of the cause of myospherulosis. Am f Clin Pathol 1993;99:249-56.
First Department of Internal Medicine, Kagawa Medical School,

M Nagai

M Fujita

J Takahara

\section{Department of}

Internal Medicine, Zentsuji National Hospital

S Oda

M Iwamoto

K Marumoto

Correspondence to: Dr M Nagai, First Department of Internal Medicine Kagawa Medica School, 1750-1, Miko-cho, Kita-gun, Kagawa 761-07, Japan

Accepted for publication 16 April 1996

\title{
Granulocyte-colony stimulating factor concentrations in a patient with plasma cell dyscrasia and clinical features of chronic neutrophilic leukaemia
}

\author{
M Nagai, S Oda, M Iwamoto, K Marumoto, M Fujita, J Takahara
}

\begin{abstract}
In order to study the pathogenesis of plasma cell dyscrasias with associated clinical features of chronic neutrophilic leukaemia, the concentration of granulocyte-colony stimulating factor (G-CSF) was measured in a patient, a 73 year old man, who underwent steroid pulse therapy. High G-CSF concentrations and leucocyte counts prior to treatment declined rapidly on administration of dexamethazone, but rose subsequently. G-CSF was not detected in primary
\end{abstract}

cultures of bone marrow cells, but large amounts of interleukin-6 were found in the culture supernatant. These observations suggest that the neutrophilia observed in the patient represented a reactive response to $\mathbf{G}-\mathbf{C S F}$ secreted from abnormal plasma cells or stromal cells rather than the existence of a genuine myeloproliferative disorder.

$(\mathcal{F}$ Clin Pathol 1996;49:858-860)

Keywords: chronic neutrophilic leukaemia, myeloma, G-CSF, steroid, regulation 


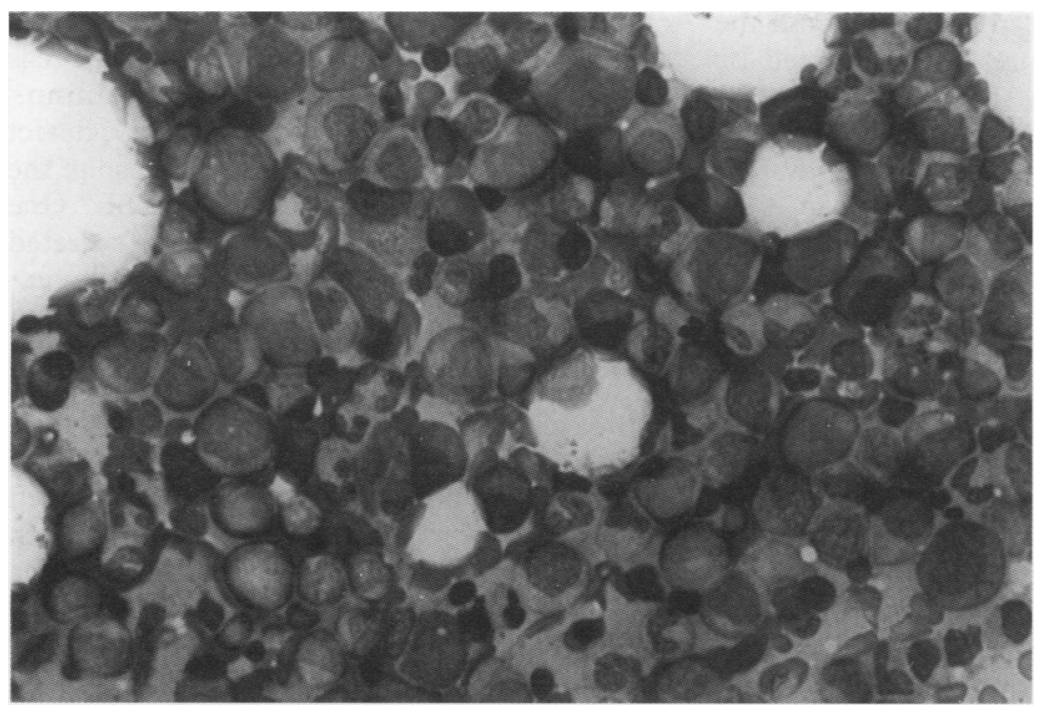

Figure 1 Morphology of bone marrow aspirate at diagnosis. Mature neutrophil expansion and increased numbers of plasma cells were observed (May-Grünwald-Giemsa; original magnification $\times 200$ ).
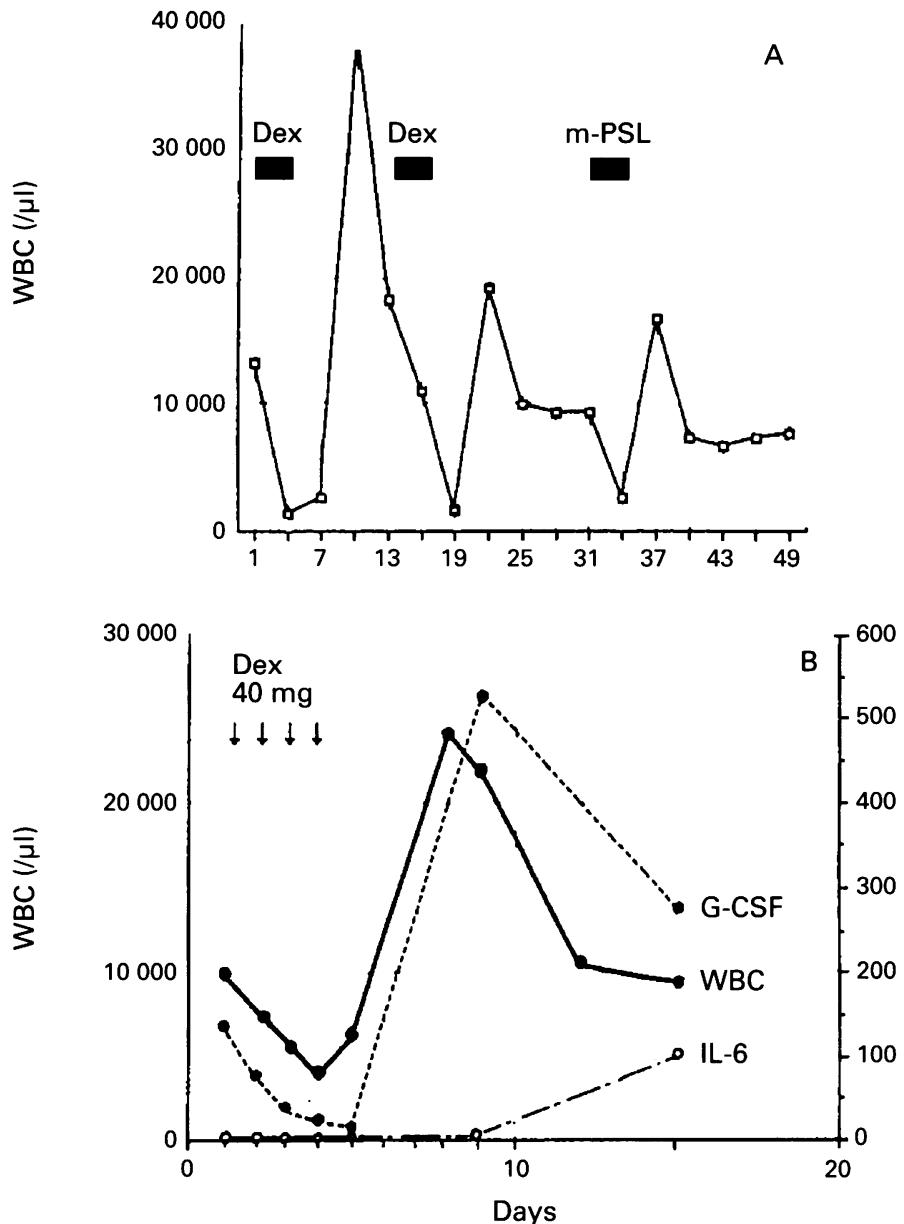

Figure 2 (A) Leucocyte counts during the three cycles of steroid pulse therapy. (B) Leucocyte counts and serum G-CSF and IL-6 concentrations during the fourth cycle of steroid pulse therapy. Dex = dexamethazone; $m-P S L=$ methyl-prednisolone; $W B C=$ white blood cells.

Chronic neutrophilic leukaemia (CNL) is a rare myeloproliferative disorder characterised by persistant neutrophilia and hepatosplenomegaly. The important criteria for its diagnosis are the exclusion of underlying diseases capable of provoking a reactive neutrophilia and chronic myelogenous leukaemia by appropriate cytogenetic and molecular studies.' Interestingly, despite the rarity of this condi- tion, more than 30 cases of CNL have been reported in association with plasma cell dyscrasias. $^{23}$ The high frequency of this unusual association involving both myeloid and lymphoid lineages raises the question whether the neutrophilia represents the existence of a genuine myeloproliferative disorder or is a reactive response. Recently, dysregulation of cytokines has been implicated in the pathogenesis of various haematological disorders. To study a possible role of abnormal cytokine production in the development of this unusual association, we examined serum granulocyte-colony stimulating factor (G$\mathrm{CSF}$ ) concentrations in a patient presenting with clinical features consistent with CNL and a plasma cell dyscrasia.

\section{Case report}

The patient, a 73 year old man, presented in April 1992 for further evaluation of a leucocytosis. A complete blood count revealed a haemoglobin of $11.4 \mathrm{~g} / \mathrm{dl}$, a leucocyte count of $28080 / \mu \mathrm{l}$, and a platelet count of $137000 / \mu \mathrm{l}$ (leucocyte differential: neutrophils, $85 \%$; lymphocytes, $9 \%$; monocytes, 3\%; eosinophils, $3 \%$ ). The bone marrow was grossly hypercellular with a predominance of mature neutrophils. An increased number of plasma cells $(7.6 \%$ of the total nucleated cells) also was observed (fig 1). An IgG, K paraprotein was detected in the serum at a concentration of $32 \mathrm{~g} / 1$ with depressed levels of $\operatorname{IgA}(0.8 \mathrm{~g} / \mathrm{l})$ and $\operatorname{IgM}(0.9 \mathrm{~g} / \mathrm{l})$. Bence-Jones protein was detected in the urine. The NAP (neutrophil alkaline phosphatase) score was 383 (normal 120). A microbiological screen was negative. Chromosome studies of marrow cells revealed a normal male karyotype, and molecular genetic analysis showed no evidence of $b c r$ gene rearrangement. The serum G-CSF concentration was $475 \mathrm{pg} / \mathrm{ml}$ and interleukin-6 (IL-6) was not detected. The patient was diagnosed as having plasma cell dyscrasia associated with CNL and monthly cycles of melphalan therapy ( $8 \mathrm{mg} /$ day/4 days) were initiated, with no obvious clinical improvement. Treatment with busulfan (2-4 $\mathrm{mg} /$ day) was instituted, which controlled the leucocyte count and paraproteinaemia until April 1994, when thrombocytopenia $(32000 / \mu \mathrm{l})$ developed. The patient was then admitted to hospital for steroid pulse therapy.

As shown in fig $2 \mathrm{~A}$, treatment with dexamethazone $(40 \mathrm{mg} /$ day for four days) rapidly reduced the leucocyte count from $13150 / \mu l$ (neutrophils, 86\%) to $1650 / \mu$ l (neutrophils, $12 \%$ ) by the fifth day of treatment. However, the leucocyte count transiently increased to $39590 / \mu l$ on the eighth day before returning to the pretreatment level by the 14 th day. Similar changes in leucocyte counts were observed during second and third clinical courses of steroid pulse therapy.

To elucidate the relation between leucocyte counts and serum G-CSF concentration, we monitored both during a fourth course of steroid therapy and simultaneously performed in vitro analysis using primary cultures of bone marrow cells aspirated prior to treatment. 
Cytokine concentrations in the serum and the supernatant of the cultures were assessed by enzyme immunoassay (Amersham Life Science, Tokyo, Japan). On administration of dexamethazone the serum G-CSF concentration rapidly declined from $137.0 \mathrm{pg} / \mathrm{ml}$ to 15.7 $\mathrm{pg} / \mathrm{ml}$ on the fifth day in parallel with the leucocyte count. However, the serum G-CSF concentration rose to $525.4 \mathrm{pg} / \mathrm{ml}$ on the ninth day, which was followed by a fall to $275 \mathrm{pg} / \mathrm{ml}$ on the 15 th day. IL- 6 was not detected $(<10$ $\mathrm{pg} / \mathrm{ml}$ ) in serum prior to the treatment, but a serum IL-6 concentration of $107 \mathrm{pg} / \mathrm{ml}$ was measured on the 15 th day (fig 2B). Meanwhile, in vitro studies revealed that large amounts of IL-6 $\left(26479 \pm 329 \mathrm{pg} / \mathrm{ml} / 2 \times 10^{6}\right.$ cells $)$ were found in the supernatant of cultures on day 6 . Unexpectedly, G-CSF was not detected $(<7$ $\mathrm{pg} / \mathrm{ml}$ ), although small amounts of granulocyte-macrophage colony stimilating factor (2 $\mathrm{pg} / \mathrm{ml}$ ) were found in the supernatant of these cultures.

\section{Discussion}

Two interesting observations were made in this study. First, high concentrations of G-CSF were found in the serum of a patient with clinical features consistent with both CNL and a plasma cell dyscrasia. Steroid pulse therapy rapidly reduced high serum G-CSF concentrations, which coincided with a decline in the patient's leucocyte counts. Interestingly, this downregulation was counteractively upregulated soon after completion of the steroid therapy. These observations suggest that the neutrophilia observed in this patient was dependent on the serum G-CSF concentration. Furthermore, the rapid and transient alterations in G-CSF concentrations suggest that steroids inhibit G-CSF synthesis or secretion from producer cells rather than killing them. Although the mechanism of genetic regulation of G-CSF synthesis is not understood fully, a recent study has identified a binding site for NF-IL-6, which is a nuclear transcriptional factor for IL- 6 synthesis, in the promotor region of the G-CSF gene. ${ }^{4}$ There may be a similar inhibitory mechanism involving IL-6 synthesis, ${ }^{5}$ where steroids antagonise the NF-IL-6 binding region and inhibit G-CSF synthesis at the level of transcription.

The second interesting observation was that high concentrations of IL- 6 were present in the supernatant of primary cultures of bone marrow cells, although we could find no detectable concentrations of IL- 6 in the serum prior to treatment. Previous studies have suggested that serum IL- 6 concentrations may not reflect those in the bone marrow. ${ }^{6}$ In our patient, it is likely that abnormal plasma cells or activated stromal cells secreted IL- 6 and supported the clonal expansion of plasma cells via an autocrine or paracrine mechanism. ${ }^{7}$ Unexpectedly, however, we failed to detect G-CSF in the culture supernatant, despite the $\Omega$ high serum concentrations of G-CSF. One $\overline{\bar{F}}$ possible explanation is that the secreted 0 G-CSF bound rapidly to its receptors ex-

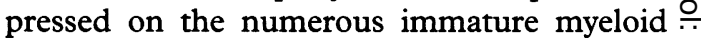
cells present in the culture and disappeared $\vec{F}$ from the supernatant. This raises the question $\frac{\sigma}{0}$ of the cell of origin of this G-CSF overproduc- $\frac{\mathrm{C}}{0}$ tion. Recent studies have demonstrated that $\overline{\frac{\bar{m}}{}}$ not only IL-6, but G-CSF mRNA is expressed in most bone marrow cells of patients with myeloma. ${ }^{8}$ It is possible that abnormal plasma cells in the patient secreted G-CSF by themselves. Alternatively, IL-1 and tumour $\vec{\omega}$ necrosis factor, which reportedly are produced $\stackrel{\omega}{\circ}$ by myeloma cells, ${ }^{9}$ may in turn activate the $\vec{?}$ stromal cells to produce G-CSF. To resolve this question, in situ hybridisation using a specific G-CSF probe might be helpful.

In conclusion, the persistent neutrophilia in this patient seems to represent a proliferative 을 reaction to the overproduction of cytokines rather than a distinct myeloproiliferative disor- 0 der. In support of this hypothesis, Standen et $\frac{?}{0}$ $a l^{10}$ have reported the case of a patient with CNL and myeloma that clearly demonstrated the polyclonal nature of myeloid cells on analysis of restriction fragment length polymorphisms using an X-linked probe. However, additional studies are required to delineate the nature of the myelopoietic stimulus in this unusual subgroup of patients with $\mathrm{CNL}$.

1 Bareford D, Jacobs B. Chronic neutrophilic leukaemia. Am $\mathcal{f}$ Clin Pathol 1980;72:837.

2 Naparstek Y, Zlotnick A, Polliack A. Coexistent chronic myeloid leukaemia and IgA monoclonal gammopathy: Report of a case and review of the literature. Am $\mathcal{F}$ Med $S c i$ 응
$1980 ; 279: 111-15$.

3 Standen GR, Jasani B, Wagstaff M, Wardrop AJ. Chronic neutrophilic leukaemia and multiple myeloma. Cancer 1990;66:162-6.

4 Akira S, Isshiki H, Sugita T, Tanabe O, Kinoshita S, Nishio $\mathrm{V}$, et al. A nuclear factor for IL-6 expression (NF-IL-6) is a member of a C/EBP family. EMBO f 1990;9:1897-906.

5 Ray A, LaForge KS, Sehgal PB. On the mechanism for efficient repression of the interleukin- 6 promotor by glucocorticoids. Mol Cell Biol 1990;10:5736-46.

6 Caligaris-Cappio F, Berui L, Gregoretti MG, Gaidano G, Gaboli $M$, Schena $M$, et al. Role of bone marrow stromal N cells in the growth of human multiple myeloma. Blood 1991;77:2688-93.

7 Klein B, Zhang XG, Lu ZY, Bataille R. Interleukin-6 in human multiple myeloma. Blood 1995;85:863-72.

8 Portier $M$, Zhang XG, Ursule E, Lees D, Jourdan M, Bataille $\mathrm{R}$, et al. Cytokine gene expression in human multiple myeloma. Br F Haematol 1993;85:514-20.

9 Lichtenstein A, Berenson J, Norman D, Chang MP, Carlile A. Production of cytokines by bone marrow cells obtained $O$ from patients with multiple myeloma. Blood 1989;74: 1266-73.

10 Standen GR, Steers FJ, Jones L. Clonality of chronic $O$ neutrophilic leukaemia associated with myeloma: analysis using the X-linked probe M27ß. ₹ Clin Pathol 1993;46: 297-8. 